\title{
Hodgkin's Disease and Autoimmune Hemolytic Anemia: A Case Report
}

\author{
Feyyaz Ozdemir ${ }^{\mathrm{a}}$ Mustafa Yilmaz $^{\mathrm{b}}$ Remzi Akdogan ${ }^{\mathrm{a}}$ Kubra Kaynar $^{\mathrm{c}}$ \\ Halil Kavgaci ${ }^{a}$ Sami Karti ${ }^{b}$ Fazil Aydin ${ }^{a}$ \\ Departments of ${ }^{a}$ Medical Oncology, ${ }^{b}$ Hematology and ${ }^{c}$ Nephrology, School of Medicine, \\ Karadeniz Technical University, Trabzon, Turkey
}

\section{Key Words}

Autoimmune hemolytic anemia · Hodgkin's disease

\begin{abstract}
Objective: To report a case of Hodgkin's disease presenting with immune hemolytic anemia. Clinical Presentation and Intervention: A 47-year-old man was admitted to hospital because of weight loss, fever, and inguinal lymph node adenopathy. Biopsy of the inguinal lymph node revealed mixed-cellularity Hodgkin's disease. Three days after starting combined chemotherapy, the patient showed evidence of autoimmune hemolytic anemia, which responded well to prednisolone. Conclusion: This case shows that clinicians should be aware of the possibility of autoimmune hemolytic anemia in patients with Hodgkin's disease presenting with anemia, and distinguish it from the anemia of chronic disease.
\end{abstract}

Copyright $(2) 2005$ S. Karger AG, Basel

\section{Introduction}

Hodgkin's disease is a distinct malignant disorder of the lymphatic system and is more common in males. The age-specific incidence of the disease is bimodal, with its greatest peak in the 3rd decade of life and a second small- er peak in the 7th decade. Histologic structure and the affected sites differ according to the age of the patients. Viral infection, environmental or occupational exposures and a genetically determined host response are believed to be etiologic factors of this disease. Patients usually have painless lymphadenopathy at initial presentation. Extralymphatic tissue involvement is rare.

Mediastinal involvement is present in half of the patients. Systemic symptoms such as fever, night sweats, and weight loss may occur with lymphadenopathy. Mild normocytic normochromic anemia is common at diagnosis; mild leukocytosis, monocytosis and lymphopenia may occur, but are more commonly seen in patients at advanced stages. These hematological findings may occur as paraneoplastic effects of the disease or due to bone marrow involvement. The diagnosis of Hodgkin's disease requires an expert hematopathologic interpretation of a lymph node specimen. Hodgkin's disease has four histologic subtypes: lymphocyte predominant, nodular sclerosing, mixed cellularity and lymphocyte depletion. Nodular sclerosing Hodgkin's disease is the most common subtype and typically affects young females while the mixed-cellularity subtype is seen in the elderly.

The stage of the disease is the most important determinant of treatment options, which include chemotherapy, radiotherapy or both [1]. Immune hemolytic anemia is very rare in Hodgkin's disease, and it was first

\section{KARGER}

Fax +4161306 1234 E-Mail karger@karger.ch www.karger.com
(C) 2005 S. Karger AG, Basel

$1011-7571 / 05 / 0143-0205 \$ 22.00 / 0$

Accessible online at:

www.karger.com/mpp
Ass. Prof. Feyyaz Ozdemir

Department of Medical Oncology, School of Medicine

Karadeniz Technical University

TR-61080 Trabzon (Turkey)

Tel. +90 462377 5483, Fax +90 462325 2270, E-Mail feyyazozdemir@yahoo.com 
Table 1. Hematologic and biochemical values of the patient

\begin{tabular}{ll}
\hline Parameters & Values \\
\hline Hemoglobin & $5.1 \mathrm{~g} / \mathrm{dl}$ \\
MCV & $103 \mathrm{fl}$ \\
Hematocrit & $13.5 \%$ \\
White blood cell count & $2.6 \times 10^{9} / 1$ \\
Platelet count & $51 \times 10^{9} / 1$ \\
Blood urea nitrogen & $15 \mathrm{mg} / \mathrm{dl}$ \\
Creatinine & $0.5 \mathrm{mg} / \mathrm{dl}$ \\
LDH & $1,266 \mathrm{IU} / 1$ \\
Direct bilirubin & $0.9 \mathrm{mg} / \mathrm{dl}$ \\
Indirect bilirubin & $2.3 \mathrm{mg} / \mathrm{dl}$ \\
ALT & $18 \mathrm{IU} / 1$ \\
AST & $31 \mathrm{IU} / 1$ \\
Total protein & $6.1 \mathrm{~g} / \mathrm{dl}$ \\
Albumin & $3.2 \mathrm{~g} / \mathrm{dl}$ \\
Vitamin B12 & $628 \mathrm{pg} / 1$ \\
Folic acid & $2.8 \mathrm{ng} / 1$ \\
Reticulocyte count & $20 \%$ \\
\hline
\end{tabular}

reported in 1966 [2]. In this report, we describe a case of Hodgkin's disease that presented with immune hemolytic anemia.

\section{Case Report}

A 47-year-old man was admitted to hospital because of weight loss, night sweats and swelling of inguinal lymph nodes. Biopsy of an inguinal lymph node was performed as a diagnostic procedure, and it was reported as mixed-cellularity Hodgkin's disease. Abdominal and thoracic CT scan revealed involvement of lymph nodes on both sides of the diaphragm. Bone marrow infiltration was also present, and the patient was found to have stage 4 disease.

Adriamycin, bleomycin, vinblastine, and dacarbazine were administered intravenously. Three days after the treatment, fever with chills and cough developed, and the patient was admitted to the emergency service. On physical examination he was found to have a fever of $40^{\circ} \mathrm{C}$; he was pale, tachycardic, and tachypneic. Rales were heard at the bases of both lungs. Hepatosplenomegaly was present. The spleen was palpable $5 \mathrm{~cm}$ below the left costal margin, and the liver edge was palpated $3 \mathrm{~cm}$ below the right costal margin. It was assumed that thrombocytopenia and leukopenia of the patient were immune mediated since bone marrow aspiration was completely normal. An antithrombocyte antibody test could not be done due to technical inadequacy.

Hematologic and blood chemistry studies were performed (table 1). Direct Coombs' test was strongly positive, and was due to a warm IgG antibody. Indirect Coomb's test and the Donath-Landsteiner test were negative. Antigen specificity tests could not be performed. Peripheral smear examination revealed $10 \%$ band cells,
$20 \%$ mature neutrophils, $68 \%$ lymphocytes and 2\% eosinophils. The reticulocyte count was 20\%. Erythrocytes were normochromic and normocytic; platelets were decreased. The diagnosis was autoimmune hemolytic anemia with an acute lower respiratory infection. Piperacillin, tazobactam and amikacin were administered intravenously. Four days after treatment, the infection was controlled and the patient felt well. Prednisolone $2 \mathrm{mg} / \mathrm{kg}$ and folic acid $5 \mathrm{mg}$ were administered orally for the autoimmune hemolytic anemia. Prednisolone therapy was continued at a dose of $2 \mathrm{mg} / \mathrm{kg}$ until the patient's hemoglobin level reached $100 \mathrm{~g} / \mathrm{l}$; thereafter the dose was lowered by $10 \mathrm{mg}$ at weekly intervals. Prednisolone was stopped at the end of the 3rd month. The levels of hemoglobin, platelets and leukocytes returned to the normal values after prednisolone and one cycle chemotherapy.

\section{Discussion}

Autoimmune hemolytic anemia may occur in lymphoproliferative diseases especially chronic lymphocytic leukemia and non-Hodgkin's lymphoma but is rarely seen in Hodgkin's disease [3, 4]. When it occurs, it is usually seen in adults rather than children [5-8]. It can be the presenting finding of the disease and it can occur during disease progression [5].

Immune-mediated hemolytic anemia is mostly seen in the nodular sclerosing subtype and in mixed cellularity subtypes, as in this case. There are only two reports showing the relationship of Hodgkin's disease with autoimmune hemolytic anemia in the literature $[8,9]$. It was reported that $90-100 \%$ of Hodgkin's disease patients with immune hemolytic anemia were in stages 3 or 4 [8]. In a study from Germany, the incidence of Coombs-positive immune hemolytic anemia in Hodgkin's disease was found to be $0.2 \%$ [9].

The direct Coomb's test must be done in patients who show evidence of hemolysis and who have high reticulocyte counts. It may be an appropriate treatment modality to give chemotherapy against primary diseases concomitantly with steroids, as in our patient.

\section{Conclusion}

This case shows that clinicians should be aware of the possibility of immune hemolytic anemia in patients with Hodgkin's disease presenting with anemia, and distinguish it from the anemia of chronic disease. 


\section{References}

1 Topuz E (ed): Klinik Onkoloji, Oral EN, Darendeliler E: Hodgkin hastalığ 1 ve Hodgkin dış 1 lenfoma. Tunc matbaasi, Istanbul 2000, pp 248-254.

2 Bowdler AJ, Glick IW: Autoimmune hemolytic anaemia as the herald case of Hodgkin's disease. Ann Intern Med 1966;65:671-677.

$>3$ Sierra RD: Coombs-positive hemolytic anemia in Hodgkin's disease: Case presentation and review of the literature. Mil Med 1991;156: 691-692.

$\checkmark 4$ Sokol RJ, Booker DJ, Stamps R: Erythrocyte autoantibodies, autoimmune haemolysis, and carcinoma. J Clin Pathol 1994;47:340-343.
$>5$ Ertem M, Uysal Z, Yavuz G, Gozdasoglu S: Immune thrombocytopenia and hemolytic anemia as a presenting manifestation of Hodgkin disease. Pediatr Hematol Oncol 2000;17: 181-185.

6 Brady-West DC, Thame J, West W: Autoimmune haemolytic anaemia, immune thrombocytopenia, and leucopenia. An unusual presentation of Hodgkin's disease. West Indian Med J 1997;46:95-96.
7 Shah SJ, Warrier RP, Ode DL, Lele HE, Yu LC: Immune thrombocytopenia and hemolytic anemia associated with Hodgkin disease. J Pediatr Hematol Oncol 1996;18:227-229.

$>8$ Case records of the Massachusetts General Hospital. Weekly clinicopathological exercises. Case 13-1997. A 32-year-old man with IgG antibody and Coombs'-positive hemolytic anemia resistant to corticosteroid therapy. $\mathrm{N}$ Engl J Med 1997;336:1235-1241.

-9 Xiros N, Binder T, Anger B, Bohlke J, Heimpel $\mathrm{H}$ : Idiopathic thrombocytopenic purpura and autoimmune hemolytic anemia in Hodgkin's disease. Eur J Haematol 1988;40:437-441. 